\title{
Effects of the use of preoperative GnRHa analogue and intra-operative mechanical tourniquet for myomectomy on surgical blood loss: A randomised controlled trial
}

\author{
Salwa Abdullahi Idle ${ }^{1}$, Helen Coles $^{2}$, Salma Ayis ${ }^{3}$, and Nitish Narvekar ${ }^{4}$ \\ ${ }^{1}$ King's College Hospital \\ ${ }^{2}$ St George's Hospital Medical School \\ ${ }^{3}$ King's College London \\ ${ }^{4}$ Kings College Hospital
}

March 31, 2021

\begin{abstract}
Objective To compare the pre-operative use of GnRH analogue and/or intra-operative use of tourniquets to determine which intervention best reduces the intraoperative blood loss at open myomectomy. Design Randomised controlled trial, partially blinded (clinician and participant) Setting Single tertiary centre Population Women requiring open myomectomy in our gynaecology outpatient clinic Methods Patients were allocated to receive either pre-operative GnRHa, intra-operative mechanical tourniquet or a combination of preoperative GnRHa and intra-operative mechanical tourniquet. Main Outcome Measure Mean intraoperative blood loss Results There was a difference in mean intra-operative blood loss of groups GnRHa ( $\mathrm{n}=14$ ) versus Tourniquet ( $\mathrm{n}=12)(752 \mathrm{ml}, 95 \%$ CI 148ml-1355ml, $\mathrm{p}=0.01)$ and groups GnRHa versus GnRHa+ Tourniquet $(\mathrm{n}=17)(804 \mathrm{ml}, 95 \%$ CI $250 \mathrm{ml}-1357 \mathrm{ml}, \mathrm{p}=0.002)$. No significant difference in intra-operative blood loss between groups Tourniquet and GnRHa+ Tourniquet (52ml, 95\% CI -630ml-526ml, p=1) were detected. A sub-analysis showed that there is no statistical significance $(\mathrm{p}=0.45)$ between mean blood loss at surgery and uterine size across the groups. Conclusions The use of a mechanical tourniquet with or without pre-operative gonadotrophin releasing hormone analogues is significantly more effective at reducing intraoperative blood loss at open myomectomy than the use of pre-operative gonadotrophin releasing hormone analogues alone Tweetable Abstract Mechanical tourniquet with or without GnRHa significantly reduces intraoperative blood loss at open myomectomy EudraCT Number 2010-019810-26
\end{abstract}

\section{Hosted file}

Myomectomy paper Final.pdf available at https://authorea.com/users/405169/articles/516185effects-of-the-use-of-preoperative-gnrha-analogue-and-intra-operative-mechanicaltourniquet-for-myomectomy-on-surgical-blood-loss-a-randomised-controlled-trial

\section{Hosted file}

Figure 1 Trial Profile.pdf available at https://authorea.com/users/405169/articles/516185effects-of-the-use-of-preoperative-gnrha-analogue-and-intra-operative-mechanicaltourniquet-for-myomectomy-on-surgical-blood-loss-a-randomised-controlled-trial 